\title{
Awareness of diabetes in the population of Greenland
}

\author{
Michael Lynge Pedersen* \\ Greenland Center for Health Research, Institute of Nursing and Health Science, University of Greenland, Nuuk, Greenland
}

Received: August 21, 2018

DOI: $10.5430 /$ cns.v7n1p56
Accepted: September 29, $2018 \quad$ Online Published: October 10, 2018

URL: https://doi.org/10.5430/cns.v7n1p56

\begin{abstract}
Objective: Type 2 diabetes (T2D) may develop slowly with few symptoms and may remain undetected for many years, leading to severe complications that potentially could have been prevented with timely diagnosis and treatment. Undiagnosed diabetes has been reported high in Greenland. However, awareness and knowledges about diabetes in the general population remains unexplored.

Methods: This study was performed as an observational cross sectional study based on telephone interview among a random sample of Greenlanders. The interview was performed in Greenlandic or Danish according to participant' preference and included information about age, gender, place of birth, place of residence, medical history of diabetes, awareness of the diabetes, risk factors, symptoms, complications, and local possibilities to get tested for diabetes.

Results: In total, telephone contact was established with 196 adults. Of those, 161 participants completed the interview while 35 were unwilling to participate in the interview corresponding to a response rate of $82 \%(161 / 196)$. The majority of responders, $85.7 \%$, were aware of diabetes and local testing possibilities. However, only around $65 \%$ were aware of risk factors of diabetes. Also, the knowledge about common symptoms of diabetes was quite low, around 50\%, and in particular low, around 40\%, among males and inhabitants in settlements.

Conclusions: The vast majority of the population was aware of diabetes. However, the present study revealed shortage of knowledge of common risk factors, symptoms, and complications to diabetes. This is challenging the effort to prevent diabetes and new alternative information strategies are needed. Furthermore, the shortage of knowledges of risk factors may not be isolated to diabetes and further studies on health literacy in Greenland are recommended.
\end{abstract}

Key Words: Diabetes care, Health delivery, Health literacy, Inuit, Greenland

\section{INTRODUCTION}

Diabetes is a chronic disease characterized by elevated blood glucose, which over time lead to serious damage to the heart, blood vessels, eyes, kidneys, and nerves. ${ }^{[1]}$

Globally, the prevalence of diabetes has increased rapidly within the last few decades now affecting around $9 \%$ of adults. ${ }^{[1]}$ Type 2 diabetes (T2D) may develop slowly and with few symptoms. As a consequence, T2D may remain undetected for many years, leading to severe complications that potentially could have been prevented with timely diagnosis and treatment. ${ }^{[2]}$ Thus, it has been estimated that $45.8 \%$ of all diabetes cases in adults are undiagnosed worldwide. ${ }^{[2]}$ Across global regions, the proportion range from $24.1 \%$ to $75.1 \%$ with middle and low income countries having the highest proportion of undiagnosed cases. ${ }^{[2]}$

Also, in Greenland the proportion of undiagnosed diabetes has been reported very high around 70\%-80\%. ${ }^{[3,4]}$ While diabetes was almost non-existing sixty years ago, ${ }^{[5-7]}$ a population survey performed around year 2000 indicated a high prevalence of diabetes affecting almost $10 \%$ of the adult

\footnotetext{
*Correspondence: Michael Lynge Pedersen; Email: milp@peqqik.gl; Address: Greenland Center for Health Research, Institute of Nursing and Health Science, University of Greenland, Nuuk, Greenland.
} 
population among Greenlanders, ${ }^{[3,4]}$ comparable to levels among Inuit and Native American populations in Canada and Alaska. ${ }^{[7]}$ These findings led to an increased focus on diabetes in the health care system in Greenland. ${ }^{[7]}$ A national diabetes initiative funded by the Danish pharmaceutical company, Novo Nordisk, was started in 2008 and ran three years. Diabetes care was reorganized nationally and significant improvements in quality of diabetes care were observed along with increasing prevalence of diagnosed diabetes 2008-2010. ${ }^{[8]}$ Afterwards, focus on diabetes care was maintained in the health care system. The diabetes initiative was extended to a lifestyle initiative within the primary health care system of Greenland and along with rest of the health care system publically financed. In addition to focus on diabetes, also management of hypertension, chronic obstructive lung disease, and general lifestyle factors like smoking, physical activity, and overweight was promoted among health care professionals. ${ }^{[9-11]}$ Recently, it was documented that $24 \%$ of the whole adult population was tested or controlled for diabetes within a two years observation period indicating high awareness of diabetes in the health care system in Greenland. Yet, the majority of tested persons were female. Thus, $32 \%$ of adult females were tested compared to only $16 \%$ among males. ${ }^{[12]}$ Despite several initiatives within the health care system to optimize management of diabetes in Greenland, unaddressed barriers may still be present. Thus, awareness of diabetes and knowledge about diabetes in the general population remains unexplored. Thus, the aim of this study was to evaluate the awareness and knowledge about diabetes in a random sample of the Greenlanders based on a telephone interview.

\section{Methods}

This study was performed as an observational cross sectional study based on telephone interview.

\subsection{Setting}

Greenland is the biggest island in the world covering approximately two million $\mathrm{km}^{2}$ and is sparsely populated by 56,000 inhabitants living in 16 towns and around 60 settlements along the coastline. The health care system aims at delivering equal health care service free of charge to every citizen in Greenland regardless of residence. ${ }^{[13]}$ This represents an overwhelming challenge in the geographically disperse populated with people living in several remote sites. Thus, around $15 \%$ of the population live in settlements and $27 \%$ in small towns with less 3,000 inhabitants. In addition, the extreme weather conditions in arctic Greenland contribute to make the population even more isolated because transportation is not always possible. Limited economic resources, diffi- culties in recruitment and retention of educated health care workers further challenge the health care service. ${ }^{[13]}$ Also, cultural and linguistic barriers exist between local patients and recruited short term health care professionals, which may account for up to a third of staff in some locations. ${ }^{[14]}$

\subsection{Study population and definition of variables}

A random sample of public telephone numbers, 400 of approximately 70,000 , was received from the national provider of telephone service in Greenland (Tele Greenland). All telephone numbers were dialed at least two times unless the number was not in use any longer. No message to call back was left. If contact was established and acceptance to participate in the interview was given after a short introduction, the interview was performed in Greenlandic or Danish based on participants preference. Only adults aged 18 years or above were interviewed. In addition to information about age, gender, place of birth, place of residence, and medical history of diabetes, the questionnaire included questions about diabetes including awareness of the disease, risk factors of getting the disease, symptoms, complications, and local possibilities to get tested for diabetes (see Table 1). The questionnaire was developed in both Danish and Greenlandic at the same time by the author in cooperation with a psychologist speaking Greenlandic and Danish fluently. Finally, it was pilot tested among ten persons.

Responders born in Greenland were considered Greenlanders, while responders born outside Greenland were considered non-Greenlanders. Responders that could mention at least one risk factor including age, obesity, physical inactivity, unhealthy eating, and diabetes in family were considered aware of risk factors. Responders that could mention at least one symptom of diabetes including polyuria, polydipsia, thirst, tiredness, weight loss, frequent skin and urogenital infections were considered aware of symptoms. Finally, responders that could mention at least one complication including atherosclerosis, stroke, or diseases in the heart, eye, kidney, or nerves were considered aware of complications to diabetes. The study was approved by the The Ethics Committee for Medical Research in Greenland (KVUG 2017-15).

\subsection{Statistics}

Normal distributed parameters were described using means and standard deviations $(S D)$. Test for normality was performed using QQ-plot. Means were compared using $t$-test. Proportions were compared using 2-sided Fischer's Exact Test. A p-value below .05 was considered significant. Statistical analyses were performed using SPSS statistical software, version 23.0 (Norusis; SPSS Inc., Chicago, IL). 
Table 1. Questions used in the survey

\begin{tabular}{l}
\hline Introduction in Greenland or Danish \\
\hline Have you ever heart about diabetes? \\
(yes/no) \\
Do you know anybody suffering of diabetes? \\
(yes/no) \\
Do you know any symptoms related to diabetes? If yes, please mention one or more? \\
(polyuria, polydipsia, thirst, tiredness, weight loss, frequent skin and urogenital infections) \\
Do you know any complications to diabetes? If yes, please mention one or more? \\
(atherosclerosis, stroke, or diseases in the heart, eye, kidney, or nerves) \\
Do you know who are at risk of getting diabetes? If yes, please mention one or more? \\
(older age, obesity, physical inactivity, unhealthy eating, and diabetes in family) \\
Do you know where to get tested for diabetes at your location? \\
(local health care clinic) \\
Have you ever been tested for diabetes yourself? \\
(yes/no) \\
Would you like to get tested for diabetes? \\
(yes/no) \\
Do you know about the health care service offered to patients with diabetes? If yes, please mention one or more? \\
(information and treatment, test of blood and urine, blood pressure, eye and feet examinations) \\
Basic information including age, place of present residence, place of birth, former history of diabetes \\
\hline
\end{tabular}

Note. Accepted answers in italic

\section{ReSUlts}

In total, 400 random telephone numbers was received from the national telephone company in Greenland (Tele Greenland). Of those, no contact could be established in 198 cases either because the number was no longer in use, the telephone was switched off, or telephone holder did not answer the one of two calls. In the remaining 202 cases, contact was established. Six persons were under 18 years old and not interviewed. Thus, in total, 196 adults were asked to participate in the interview. Of those, 161 participants completed the interview while 35 were unwilling to participate in the interview corresponding to a response rate of $82 \%$ (161/196). No information was obtained among persons unwilling to participate. No difference in mean age among females 47.1 years old $(S D=17.6)$ and males 49.6 years old $(S D=17.1)$ was observed $(p=.712)$. The youngest participant was 18 years old and the oldest 85 years old. Basic characteristics for all responders are illustrated in Table 1 including figures from Greenland Statistics for all Greenland. ${ }^{[15]}$

Awareness of diabetes among male and female responders, and among responders living in settlements and town are illustrated in Table 2. The vast majority (85.7\%) of all responders have heard about diabetes and knew $(77.6 \%)$ somebody diagnosed with diabetes. Also, most responders (82.6\%) were aware of local testing possibilities and more than half (54.7\%) of the responders were already tested for diabetes.

Fewer, $65.2 \%$, were aware of risk factors of developing dia- betes and only around 50\% were aware of symptoms of and complications to diabetes (see Table 3). Females tended to be more aware of symptoms, $58.2 \%$ vs. $42.3 \%$, and complications to diabetes, $55.7 \%$ vs. $38.4 \%$, compared to males.

Table 2. Basic characteristics among responders and adults aged 18 or above in Greenland

\begin{tabular}{ll}
\hline Variable & Responders (N = 161) \\
\hline Male \% & 45.3 \\
$(95 \% \mathrm{CI})$ & $(37.7-53.0)$ \\
$(\mathrm{n})$ & $(73)$ \\
Greenlander \% & 93.2 \\
$(95 \% \mathrm{CI})$ & $(89.3-97.1)$ \\
$(\mathrm{n})$ & $(150)$ \\
Living in towns \% & 79.5 \\
$(95 \% \mathrm{CI})$ & $(73.3-85.7)$ \\
$(\mathrm{n})$ & $(128)$ \\
\hline
\end{tabular}

Four persons were diagnosed with diabetes corresponding to a prevalence of diagnosed diabetes at $2.5 \%(95 \% \mathrm{CI} ; 0.1 \%$ $4.9 \%)$. Of those, all (100\%) were aware of the local diabetes health service compared to $33.1 \%$ (52/157) among persons without diabetes $(p=.014)$.

\section{Discussion}

The vast majority of responders, $85.7 \%$, were aware of diabetes and local testing possibilities. Furthermore, around three out of four responders new somebody diagnosed with diabetes and more than half of the responders were already 
tested for diabetes indicating a relative high awareness of diabetes in the population of Greenland. However, only around $65 \%$ were aware of risk factors of diabetes indicating that further information of diabetes may be needed in the near the future to address modifiable risk factors. Also, the knowledge about common symptoms of diabetes was quite low, around $50 \%$, and in particular low, around $40 \%$, among males and inhabitants in settlements. Thus, people living in the settlements had lower knowledge of symptoms, were less informed about local testing possibilities and diabetes health care services compared to responders living in the towns indicating room for improvement of diabetes awareness in the settlements.

Table 3. Awareness of diabetes among responders

\begin{tabular}{|c|c|c|c|c|c|c|c|}
\hline Awareness & $\begin{array}{l}\text { Females } \\
\mathbf{N}=\mathbf{8 8}\end{array}$ & $\begin{array}{l}\text { Males } \\
\mathbf{N}=73\end{array}$ & $p$ & $\begin{array}{l}\text { Settlement } \\
\mathbf{N}=\mathbf{3 3}\end{array}$ & $\begin{array}{l}\text { Town } \\
\mathrm{N}=138\end{array}$ & $p$ & $\begin{array}{l}\text { Total } \\
\mathrm{N}=161\end{array}$ \\
\hline Heart about diabetes \% (n) & $\begin{array}{l}88.6 \\
(78)\end{array}$ & $\begin{array}{l}82.2 \\
(60)\end{array}$ & .266 & $\begin{array}{l}78.8 \\
(26)\end{array}$ & $\begin{array}{l}81.2 \\
(112)\end{array}$ & .262 & $\begin{array}{l}85.7 \\
(138)\end{array}$ \\
\hline Know somebody with diabetes \% (n) & $\begin{array}{l}75.0 \\
(66)\end{array}$ & $\begin{array}{l}80.8 \\
(59)\end{array}$ & .449 & $\begin{array}{l}66.7 \\
(22)\end{array}$ & $\begin{array}{l}74.6 \\
(103)\end{array}$ & .103 & $\begin{array}{l}77.6 \\
(125)\end{array}$ \\
\hline Could name one symptom of \% (n) & $\begin{array}{l}58.0 \\
(51)\end{array}$ & $\begin{array}{l}42.5 \\
(31)\end{array}$ & .056 & $\begin{array}{l}33.3 \\
(11)\end{array}$ & $\begin{array}{l}51.4 \\
(71)\end{array}$ & .031 & $\begin{array}{l}50.9 \\
(82)\end{array}$ \\
\hline Could name one complications \% (n) & $\begin{array}{l}55.7 \\
(49)\end{array}$ & $\begin{array}{l}38.4 \\
(28)\end{array}$ & .039 & $\begin{array}{l}33.3 \\
(11)\end{array}$ & $\begin{array}{l}47.8 \\
(66)\end{array}$ & .079 & $\begin{array}{l}47.8 \\
(77)\end{array}$ \\
\hline Could name one risk factors $\%(\mathrm{n})$ & $\begin{array}{l}64.8 \\
(57)\end{array}$ & $\begin{array}{l}65.8 \\
(48)\end{array}$ & $>.999$ & $\begin{array}{l}57.6 \\
(19)\end{array}$ & $\begin{array}{l}62.3 \\
(86)\end{array}$ & .312 & $\begin{array}{l}65.2 \\
(105)\end{array}$ \\
\hline Know about local testing possibilities \% (n) & $\begin{array}{l}83.0 \\
(73)\end{array}$ & $\begin{array}{l}82.2 \\
(60)\end{array}$ & $>.999$ & $\begin{array}{l}66.7 \\
(22)\end{array}$ & $\begin{array}{l}80.4 \\
(111)\end{array}$ & .010 & $\begin{array}{l}82.6 \\
(133)\end{array}$ \\
\hline Ever tested for diabetes $\%$ (n) & $\begin{array}{l}54.5 \\
(48)\end{array}$ & $\begin{array}{l}54.8 \\
(40)\end{array}$ & $>.999$ & $\begin{array}{l}51.5 \\
(17)\end{array}$ & $\begin{array}{l}51.4 \\
(71)\end{array}$ & .700 & $\begin{array}{l}54.7 \\
(88)\end{array}$ \\
\hline Would like to get tested for diabetes $\%$ (n) & $\begin{array}{l}65.9 \\
(58)\end{array}$ & $\begin{array}{l}57.5 \\
(41)\end{array}$ & .255 & $\begin{array}{l}75.8 \\
(25)\end{array}$ & $\begin{array}{l}53.6 \\
(74)\end{array}$ & .072 & $\begin{array}{l}61.5 \\
(99)\end{array}$ \\
\hline $\begin{array}{l}\text { Aware of the local diabetes care health } \\
\text { service } \%(n)\end{array}$ & $\begin{array}{l}35.2 \\
(31)\end{array}$ & $\begin{array}{l}34.2 \\
(25)\end{array}$ & $>.999$ & $\begin{array}{l}18.2 \\
(6)\end{array}$ & $\begin{array}{l}36.2 \\
(50)\end{array}$ & .026 & $\begin{array}{l}34.8 \\
(56)\end{array}$ \\
\hline
\end{tabular}

\subsection{Strengths and limitations}

This is the first survey to study awareness of diabetes in Greenland. Furthermore, the study covered the whole nation and was based on a random sample of telephone numbers. The response rate was high since $82 \%$ of eligible participants agreed to participate. However, a number of limitations were observed. First of all, the absolute number of responders was limited due to lack of contact in almost half of the received telephone numbers. On the other hand, there was no reason to believe that any systematic bias was introduced related to lack of contact. Furthermore, the proportion of males $(45.3 \%)$ and persons living in towns $(79.5 \%)$ among responders were slightly lower compared to $53.4 \%$ and $87.6 \%$ in the general adult population of Greenland. Also, the proportion of Greenlanders (93.2\%) among responders was slightly higher than $87.0 \%$ in the general adult population of Greenland. This represents a limitation in the generalization of the results. Thus a higher proportion of females may have tended to slightly overestimate the awareness on risk factors whereas the overrepresentations of persons living outside towns may have tended to underestimate the awareness of symptoms of diabetes and knowledges about local testing possibilities. However, the relative high awareness of diabetes as a disease in the population of Greenland documented in this study and the high proportion of responders tested for diabetes is in line with a recent study focusing on diagnostic activity of diabetes in Greenland. ${ }^{[12]}$ Thus, almost a fourth of the adult population (20-79 years old) was tested for diabetes within two years. ${ }^{[12]}$ In addition, the prevalence of diagnosed diabetes at $2.5 \%(95 \% \mathrm{CI} ; 0.1 \%-4.9 \%)$ estimated in present study is in good accordance with a recent estimate of prevalence of diagnosed diabetes in Greenland at $2.53 \%$ to among adults aged $20-79^{[16]}$ indicating that the present study population is actually representative for the adult population in Greenland.

\subsection{Awareness of diabetes}

The relative high awareness of diabetes and knowledges about local testing possibilities in Greenland may have been a result of the increased focus on diabetes in the health care system in Greenland including a national diabetes project running from 2008 to 2011 and afterwards the lifestyle initia- 
tive running from 2011 focusing on management of diabetes and other chronic diseases. ${ }^{[9]}$ On the other hand, clearly, the knowledge of risk factors of diabetes was relatively low, $65 \%$. Consequently, the possibility to act on modifiable risk factors in order to prevent diabetes is limited. The observed gender difference is in line with a proportion of males in general paying less attention to health in Greenland. Thus, recent studies has revealed that fewer males than females attend the health care system in Greenland annually. ${ }^{[12,17]}$ This is line with a global trend of men using the health care system less frequently than females, a global trend also observed in the other Nordic countries. ${ }^{[18-20]}$ Thus, further and alternative strategies to improve knowledges about diabetes and prevention are warranted. In particular, strategies should target males, but also inhabitant in settlements. Events targeting males including access to information and testing outside the traditional health care system in working sites and leisure facilities may be explored as part of the strategy. This could also be done in settlements with traveling preventive health care teams. This could be done with inspiration from earlier successfully experiences in Greenland combatting tuberculosis with a sailing clinic, Misigssut, a ship outfitted with equipment for making X-rays, chest sputum examinations, tuberculin test, and Bacillus Calmette-Guérine vaccination. ${ }^{[21]}$ Furthermore, mobile health care clinics have been reported to a cost-effective way of delivering diabetes care among aboriginals living in British Colombia, Canada. ${ }^{[22]}$ Also within the traditional health care system, health care providers are recommended to have conversation about risk factors of diabetes whenever appropriate. Most important is monitoring of eventually effects since no clear evidence exists of how to deal with the gender health gap. ${ }^{[23,24]}$

\section{Conclusions}

Despite the majority of the responders actually being aware of diabetes and local testing possibilities, the present study revealed shortage of knowledge of common risk factors, symptoms, and complications to diabetes, in particular among males and inhabitants in settlements. This is challenging the effort to prevent diabetes and new alternative information strategies are needed. Furthermore, the shortage of knowledges of risk factors may not be isolated to diabetes and further studies on health literacy in Greenland are recommended.

\section{FUNDING}

The project was financed by Lilly \& Herbert Hansens Fond.

\section{CONFLiCTS OF INTEREST DisClosure}

The authors declare they have no conflicts of interest.

\section{REFERENCES}

[1] WHO I Diabetes. WHO. [cited 2016 Feb 16]. Available from: http: //www.who.int/mediacentre/factsheets/fs312/en/

[2] Beagley J, Guariguata L, Weil C, et al. Global estimates of undiagnosed diabetes in adults. Diabetes Res Clin Pract. $2014 \mathrm{Feb}$; 103(2): 150-60. PMid: 24300018. https://doi.org/10.1016/j.diab res. 2013.11.001

[3] Jørgensen ME, Bjeregaard P, Borch-Johnsen K. Diabetes and impaired glucose tolerance among the inuit population of Greenland. Diabetes Care. 2002 Oct; 25(10): 1766-71. PMid: 12351475. https://doi.org/10.2337/diacare.25.10.1766

[4] Jørgensen ME, Borch-Johnsen K, Witte DR, et al. Diabetes in Greenland and its relationship with urbanization. Diabet Med J Br Diabet Assoc. 2012 Jun; 29(6): 755-60. PMid: 22132939. https://doi.org/10.1111/j.1464-5491.2011.03527.x

[5] Sagild U, Littauer J, Jespersen CS, et al. Epidemiological studies in Greenland 1962-1964. I. Diabetes mellitus in Eskimos. Acta Med Scand. 1966 Jan; 179(1): 29-39. PMid: 5904457. https: //doi.org/10.1111/j.0954-6820.1966.tb05430.x

[6] Kromann N, Green A. Epidemiological studies in the Upernavik district, Greenland. Incidence of some chronic diseases 1950-1974 Acta Med Scand. 1980; 208(5): 401-6. PMid: 7457208.

[7] Pedersen ML. Diabetes mellitus in Greenland. Dan Med J. 2012 Feb; 59(2): B4386. PMid: 22293056.

[8] Pedersen ML, Jacobsen JL. Improvement of diabetes care in a small but geographically widely spread population in Greenland.
Effects of a national diabetes care programme. Diabet Med J Br Diabet Assoc. 2011 Nov; 28(11): 1425-32. PMid: 21615488 https://doi.org/10.1111/j.1464-5491.2011.03337.x

[9] Reiss AE, Pedersen ML. Smoking among patients in the primary health care system in Nuuk, Greenland. Clin Nurs Stud. 2014 Sep 10; 2(4): 74.

[10] Bundgaard M, Jarb $\varnothing 1$ DE, Paulsen MS, et al. Prevalence of the use of antihypertensive medications in Greenland: a study of quality of care amongst patients treated with antihypertensive drugs. Int J Circumpolar Health. 2012 Jun 13 [cited 2017 Nov 3]; 71. Available from: https://www.ncbi.nlm.nih.gov/pmc/articles/PMC3 417658/

[11] Nielsen LO, Olsen S, Jarbøl DE, et al. Spirometry in Greenland: a cross-sectional study on patients treated with medication targeting obstructive pulmonary disease. Int J Circumpolar Health. 2016 Dec 8 [cited 2017 Nov 6]; 75. Available from: https://www.ncbi.nlm .nih.gov/pmc/articles/PMC5148803/

[12] Pedersen ML. High awareness of diabetes in the health care system in Greenland measured as a proportion of population tested with glycated haemoglobin within 2 years. Diabetol Metab Syndr. 2017; 9: 30. PMid: 28473873. https://doi .org/10.1186/s13098-0 17-0230-4

[13] Niclasen B, Mulvad G. Health care and health care delivery in Greenland. Int J Circumpolar Health. 2010 Dec 18; 69(5): 437-87. PMid: 21118636. https://doi.org/10.3402/ijch.v69i5.17691 
[14] Lægemanglen bliver værre og værre. Sermitsiaq AG. [cited 2018 Sep 24]. Available from: http://www.sermitsiaq.ag/node/20842 8

[15] Grønlands Statistik. [cited 2018 Aug 16]. Available from: http: //www.stat.gl/default.asp?lang=en

[16] Viskum ES, Pedersen ML. Prevalence of diagnosed diabetes and quality of care among Greenlanders and non-Greenlanders in Greenland. Diabetes Res Clin Pract. 2016 Nov; 121: 91-8. PMid: 27690318. https://doi.org/10.1016/j.diabres.2016.09.006]

[17] Pedersen ML, Rolskov A, Jacobsen JL, et al. Frequent use of primary health care service in Greenland: an opportunity for undiagnosed disease case-finding. Int J Circumpolar Health. 2012; 71: 18431. https://doi.org/10.3402/ijch.v71i0.18431

[18] Banks I, Baker P. Men and primary care: improving access and outcomes: MEN'S HEALTH. Trends Urol Mens Health. 2013 Sep; 4(5): 39-41. https://doi.org/10.1002/tre.357

[19] WHO । The men's health gap: men must be included in the global health equity agenda. WHO. [cited 2018 Aug 17]. Available from: http://www.who.int/bulletin/volumes/92/8/13-1 32795/en/
[20] Krakau I. Trends in Use of Health Care Services in Swedish Primary Care District. A Ten Year Perspective. Scand J Prim Health Care. 1992 Jan; 10(1): 66-71. PMid: 1589667. https://doi.org/10.3 109/02813439209014038

[21] Horwitz O, Penelope G, Payne B, et al. Epidemiological Basis of tuberculosis Eradication. Bull Wld Hlth Org. 1966; 35: 509-26.

[22] Jin AJ, Martin D, Maberley D, et al. Evaluation of a mobile diabetes care telemedicine clinic serving Aboriginal communities in Northern British Columbia, Canada. International Journal of Circumpolar Health. 2012; 63(Suppl 2): 124-128. https://doi.org/10.340 2/ijch.v63i0.17871

[23] Robertson LM, Douglas F, Ludbrook A, et al. What works with men? A systematic review of health promoting interventions targeting men. BMC Health Serv Res. 2008 Jul 3; 8: 141. PMid: 18598339. https://doi.org/10.1186/1472-6963-8-141

[24] Elterman DS, Pelman RS. Male health: a new paradigm, strategies for care delivery, advocacy, education and research. Rev Médica Clínica Las Condes. 2014 Jan 1; 25(1): 35-9. https ://doi.org/ $10.1016 / \mathrm{S} 0716-8640$ (14) $70008-2$ 